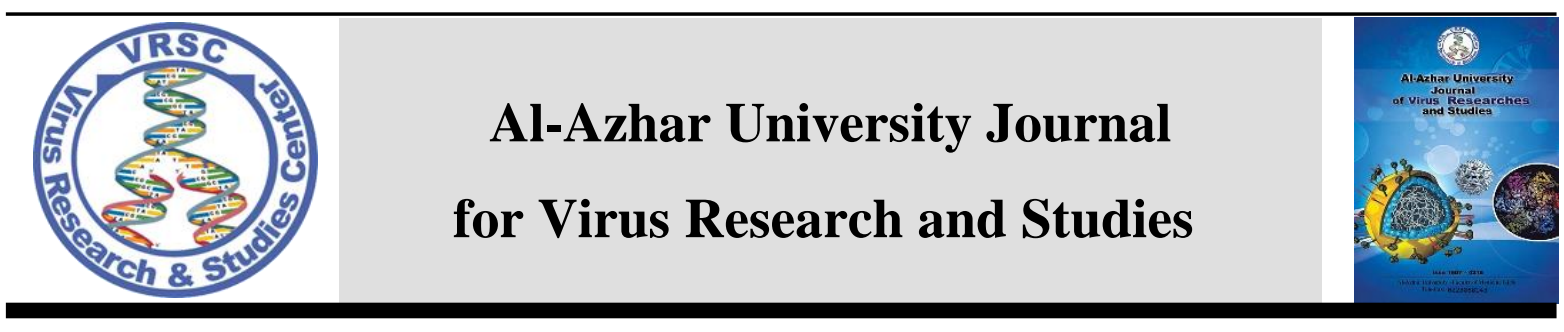

\title{
Assessment of the Therapeutic Effect of Probiotic Lactobacilli Alone and in Combination with Metronidazole in Murine Giardiasis
}

\author{
Asmaa A. Mazroue ${ }^{1 *}$, Azza A. Elnokaly ${ }^{1}$, Fatma M. El-lessy ${ }^{1}$, Eman N. Elbatrawy ${ }^{2}$ and \\ Marwa M. Helal ${ }^{2}$ \\ ${ }^{1}$ Department of Medical Parasitology, Faculty of Medicine for Girls, Al-Azhar \\ University
}

${ }^{2}$ Regional Center for Mycology and Biotechnology, Cairo, Egypt.

*E-mail: asmaaahmed.medg@azhar.edu.eg

\begin{abstract}
Giardia lamblia is considered one of the most common intestinal parasites that infect human. It is the causative agent of giardiasis, a major cause of diarrheal illness. Current recommended treatment usually accomplished using one of several drugs. However, resistance is increasing, and new alternatives are being sought. Currently the interest in alternative biotherapeutic strategies which have included natural interventions such as probiotic Lactobacillus bacteria which displays antiprotozoal effect is required. The present study was conducted on 57 laboratory bred Swiss albino mice provided by animal house in Theodor Bilharz Research Institute to evaluate the effect of Lactobacillus casei on Giardia lamblia versus the commercially used drug metronidazole in experimentally infected mice. The mice were divided into two main groups: group (A) which included normal non infected mice and group (B) which included infected mice. Each group was subsequently divided into 4 subgroups (control, treated with metronidazole, treated with L. casei and treated with both metronidazole \& L. casei) in addition to prophylactic subgroup in group (B) (received L.casei seven days before and 10 days after infection directly then for ten days after approval of infection by Giardia cysts). The mice were infected with Giardia cysts in a dose of $10^{4} \pm 10$ cysts/mouse. Parasitological, histopathological and immunohistochemical assessments of the drug effect were done. The obtained results of infected treated group were plotted in comparison to healthy control, non-infected treated mice and infected control. Parasitological assessment was done through counting of cysts output of infected mice 7 and 10 days after starting treatment. Histopathological and immunohistochemical assessments were done by examining sections of the duodenum. There was a significant reduction of the excreted cysts count in infected treated subgroups. The highest cyst reduction was in prophylactic and treated with both L.casei \& metronidazole subgroups compared to metronidazole treated and infected control. Histopathological examination of infected control revealed profound effect on the structure of the intestinal mucosa with diffuse loss of brush border of intestinal villi. After treatment there was remarkable improvement of these histopathological findings especially in prophylactic subgroup compared to metronidazole treated and infected control. Immunohistochemical
\end{abstract}


staining revealed marked increase in IgA secretory plasma cells in prophylactic and treated with both L.casei \& metronidazole subgroups compared to infected control and metronidazole treated mice. The results achieved that probiotics have a promise in the treatment of giardiasis. The protective response of probiotic in mice is better when Lactobacilli were administered for many days before infection.

Keywords: Giardia lamblia, Probiotic, Lactobacillus casei Metronidazole.

\section{Introduction}

Giardia lamblia is a flagellate intestinal protozoa that infects humans and several animal species. It is one of the most common pathogens responsible for diarrhoea [1]. It occurs frequently in both developing and developed countries [2]. It affects children, adults, malnourished and immunocompromised individuals [3].

Between 2001 and 2017, giardiasis has been reported in different localities of Egypt and the prevalence rate ranged between $10 \%$ and $75 \%$ [4].

Clinical manifestations range from asymptomatic to transient or persistent acute stage with steatorrhea, intermittent diarrhea, flatulence, malabsorption and weight loss or chronic stage that can mimic gallbladder or peptic ulcer diseases [5]. Additionally, those suffering from giardiasis often have difficulty in absorbing lactose, vitamin A, folate and vitamin B12. In children, prolonged giardiasis can cause failure to thrive and may impair mental development [6].

A variety of chemotherapeutic agents such as 5-nitroimidazole compounds, quinacrine, furazolidone, paromomycin, benzimidazole compounds and nitazoxanide have been used in giardiasis. However, treatment with these drugs is associated with several adverse reactions e.g., nausea, headache, vomiting, fever, diarrhea, dizziness, general body discomfort, loss of appetite, metallic or bitter taste in mouth and severe allergic reactions (rash, difficulty in breathing, tightness in the chest and swelling of the mouth, face, lips or tongue) making them unsuitable for use [7]. The low compliance in patients, occurrence of resistant strains and adverse effects of the chemotherapeutic agents have inspired the scientists to look for alternative natural bio-interventions such as probiotics that are safe, inexpensive and effective in improving the cause of intestinal parasitosis [8].

Probiotics are live microorganisms which when administered in adequate amounts provide a health benefits on the host. It beneficially affects the gastrointestinal balance by improving or restoring of gut flora [National Institutes of Health, 2018]. Probiotics are believed to provide an important role in human health by providing a protective effect on the microbiota in the gastrointestinal tract (GIT) through both colonization and transient activity, depending on the species. The effects of probiotics have been most studied in gastrointestinal (GI) conditions such as acute infectious diarrhea, inflammatory bowel disease (IBD) and irritable bowel syndrome (IBS). In parasitological field, probiotic was found to be effective against Cryptosporidium parvum, Giardia duodenalis, Ascaris suum, Schistosoma mansoni, Toxocara canis, Trichinella spiralis, Babesia microti and Trypanosoma cruzi [9].

The present study aimed to evaluate the effect of probiotic Lactobacillus casei (L.casei) alone and in conjunction with metronidazole in mice infected with G.intestinalis.

\section{MATERIALS AND METHODS}

\subsection{Experimental animals:}

This study was carried out on 57 laboratory bred female Swiss albino mice 3-4 weeks age with a weight range from 20-25 grams. They were obtained from and housed in animal house of Theodor Bilharz Research 
Institute (TBRI). The mice were divided into two main groups:

Group A (GA): Non infected group: comprised of 17 healthy mice which were subdivided into 4 subgroups:

S.G.1A: Four non infected non treated mice (healthy control).

S.G.2A: Four non infected mice which were received MTZ

S.G.3A: Four non infected mice which were received L.casei.

S.G.4A: Five non infected mice which were received both MTZ and L.casei .

Group B (GB) Infected group: comprised of 40 infected mice which were subdivided into 5 subgroups:

S.G.1B: Eight mice which were infected with Giardia cysts and did not receive any treatment (Infected control).

S.G.2B: Eight mice which were treated with MTZ.

S.G.3B: Eight mice which were received L.casei seven days before and ten days after infection directly (prophylactic).

S.G.4B: Eight mice which were treated with L.casei .

S.G.5B: Eight mice which were treated with both MTZ \& L.casei .

* All subgroups (S.G.2, 3, 4, 5B) received L.casei after approval of infection for ten days.

\subsection{Isolation and counting of Giardia cyst:}

Giardia cysts which were used for infection of mice were obtained from patients complaining from diarrhea attending the outpatient clinic of El Zahraa University Hospital. The stool samples of infected patients were collected in sterile clean stool cups. They were examined for detection of Giardia cysts and exclusion of other parasites by coproscopic examination, wet smears (with \& without iodine) and formalin ethyl acetate sedimentation concentration [10]. According to [11] cysts were counted by using hemocytometer. The number of cysts was expressed per gram of stool.

\subsection{Animal infection:}

Each mouse in the infected group was infected with Giardia cysts orally in a dose of $10^{4} \pm 10$ cysts/mouse [12]. Fecal samples of mice were collected after infection and subjected to parasitological examination every other day to ensure that all mice in the infected group have been infected. The presence of Giardia cysts was proved in stool of mice 10 days post infection by coproscopic examination, wet smears (with \& without iodine) and formalin ethyl acetate sedimentation concentration [10].

\subsection{Isolation of bacteria:}

Preparation of Lactobacillus casei (L.casei) was done in Regional Center for Mycology and Biotechnology Al-Azhar University, using yoghurt samples which were collected from super markets in Egypt. The bacteria Lactobacillus spp. was isolated from yoghurt samples by using modified [13] (MRS broth) and MRS agar media. Additionally, $0.05 \%$ cysteine was added to MRS to improve the specificity of this medium for isolation of Lactobacillus [13].

\subsection{Treatment administration:}

Preparation and administration of both MTZ and L.casei were done at therapeutic chemical laboratory of TBRI and were given for 10 days post infection. Metronidazole (Flagyl, Amriya Pharmaceutical Industries, Alexandria, Egypt), suspension form $125 \mathrm{mg} / \mathrm{ml}$ was purchased from a local pharmacy and was given orally in a dose of $0.3 \mathrm{mg} / \mathrm{mouse} /$ day for 10 consecutive days [14]. Mice in noninfected L.casei (S.G .3A) and MTZ \& L.casei (S.G.4A) subgroups and infected L.casei ( S.G.4B) and MTZ \& L.casei (S.G.5B) subgroups were fed orally with L. casei $1 \times 10^{9} \mathrm{CFU} / 0.1 \mathrm{ml}$ (colony forming 
units /0.1 milliliter) single oral dose per day. Treatment started 10 days post infection for 10 days while, mice in prophylactic (S.G.3B) subgroup received L.casei seven days before and 10 days after infection directly then for ten days after approval of infection by Giardia cysts [15].

\subsection{Parasitological examination:}

Stool specimens were collected at 7 and 10 days after starting treatment to count the number of Giardia cyst per gram of stool using hemocytometer counting chamber [11]. Parasitological examination was performed at parasitological department of Al-Azhar Faculty of Medicine for Girls and TBRI. Sacrification of all mice was done by rapid decapitation 10 days after completing the treatment.

\subsection{Histopathological examination:}

After sacrification of mice, parts of duodenum were removed, opened longitudinally, fixed in 10\% formaldehyde, sections of $4 \mu \mathrm{m}$ thickness were stained with hematoxylin \& eosin and stained sections were studied histopathological [16].

\subsection{Immunohistochemical examination:}

Sections of $4 \mu \mathrm{m}$ thickness were stained with immunohistochemical staining. IgA expression was evaluated according to $\mathrm{H}$ score [17]. Histopathology and immunohistochemistry studies were performed at the Histopathological department at TBRI.

\subsection{Data analysis:}

All values were expressed as means $( \pm \mathrm{SD})$. Means were compared by t-test, Anova and significant values were established at $\mathrm{p} \leq$ 0.05 .

\subsection{Ethical Considerations:}

The protocol of this study was approved by ethical committee of Faculty of Medicine for Girls, Al-Azhar University and TBRI.
Stool samples from patients complaining from diarrhea were collected after informing them verbally and taking their consent.

\section{Experimental Results}

The results obtained were represented in the following chart, table, and figures.

\subsection{Parasitological results:}

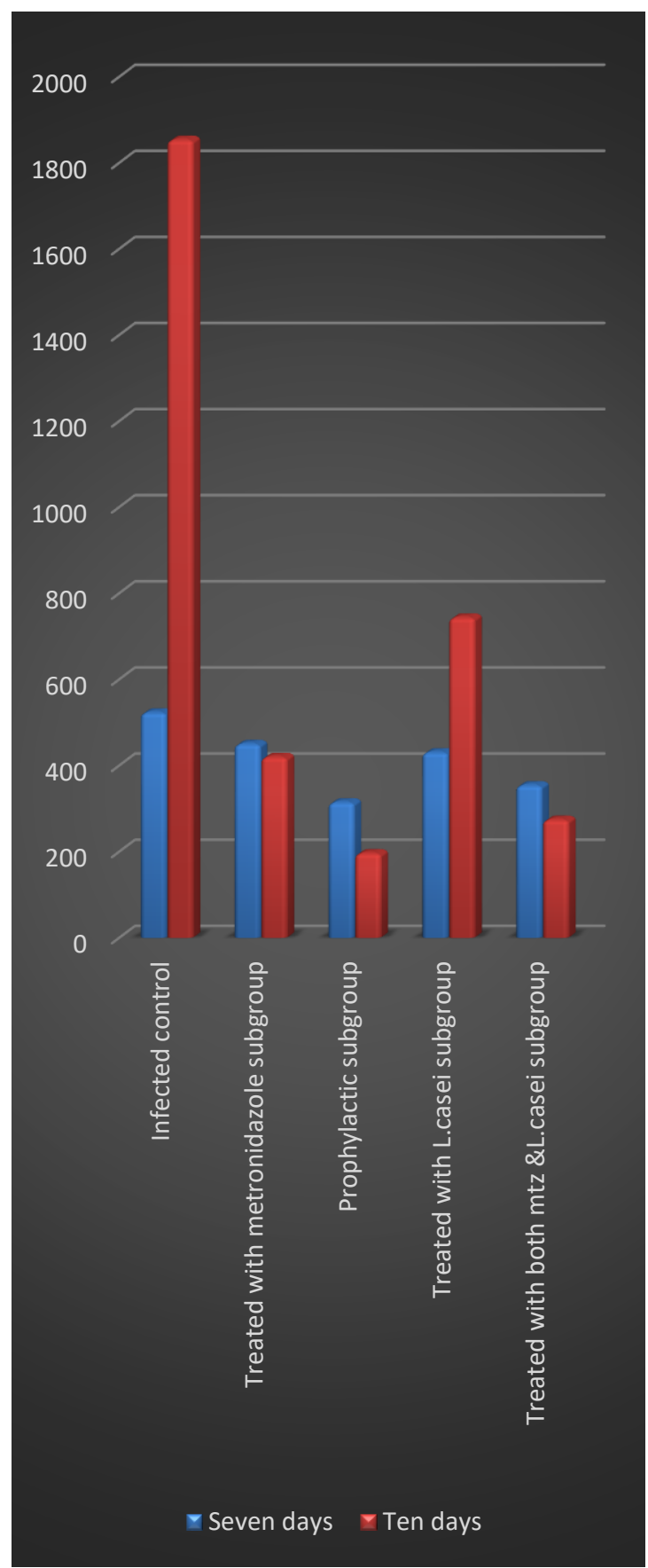

Chart 1. The mean number of Giardia cysts/g in stool of the infected control and different treated subgroups, seven- and ten-days post treatment. 
Table 1. Comparison between the mean number of Giardia cysts/g in stool of the infected control (S.G.1B) and different treated (S.G.2, 3, 4,5B) subgroups, seven- and ten-days post treatment.

\begin{tabular}{|c|c|c|c|c|c|}
\hline \multicolumn{1}{|c|}{ Subgroups } & & & & \\
Days \\
after \\
treatment
\end{tabular}

\subsection{Histopathological results:}

\subsubsection{Non infected group:}

1- Healthy control subgroup (S.G.1A):

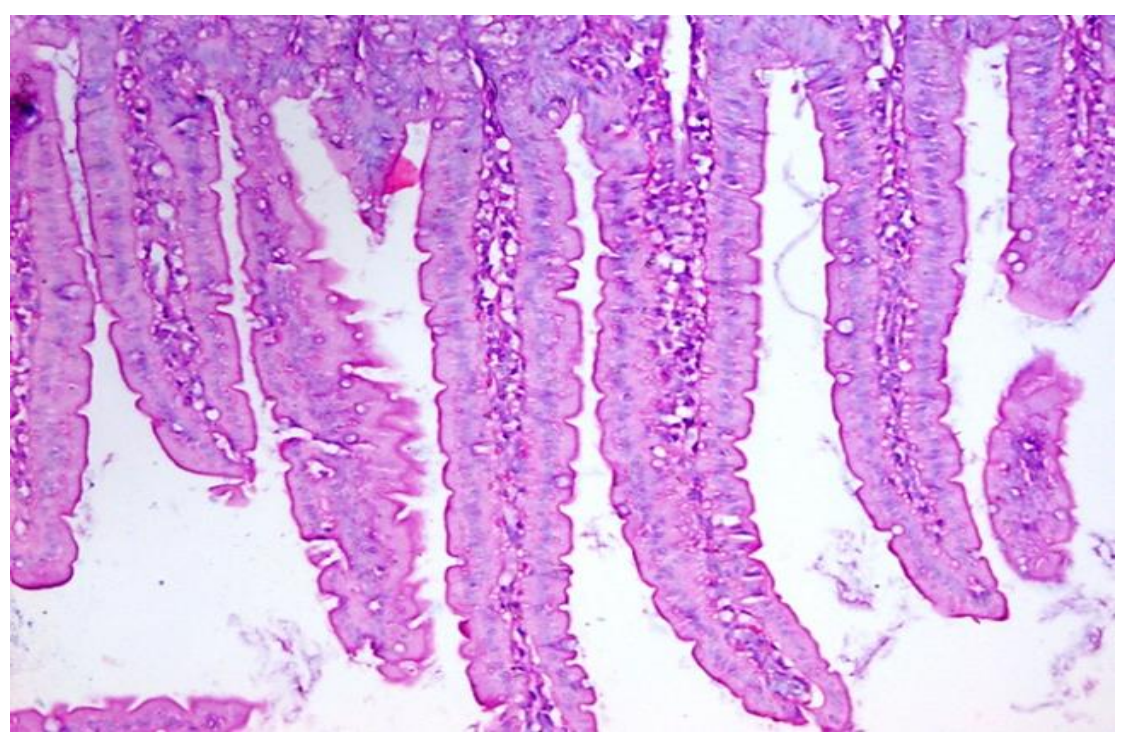

Figure 1. (Healthy control subgroup): Sections in small intestine of (S.G.1A), showed normal villous pattern and moderate number of goblet cells (H\&E stain X100). 
2- Non infected received MTZ, L.casei \& both of them (S.G.2, 3,4A):

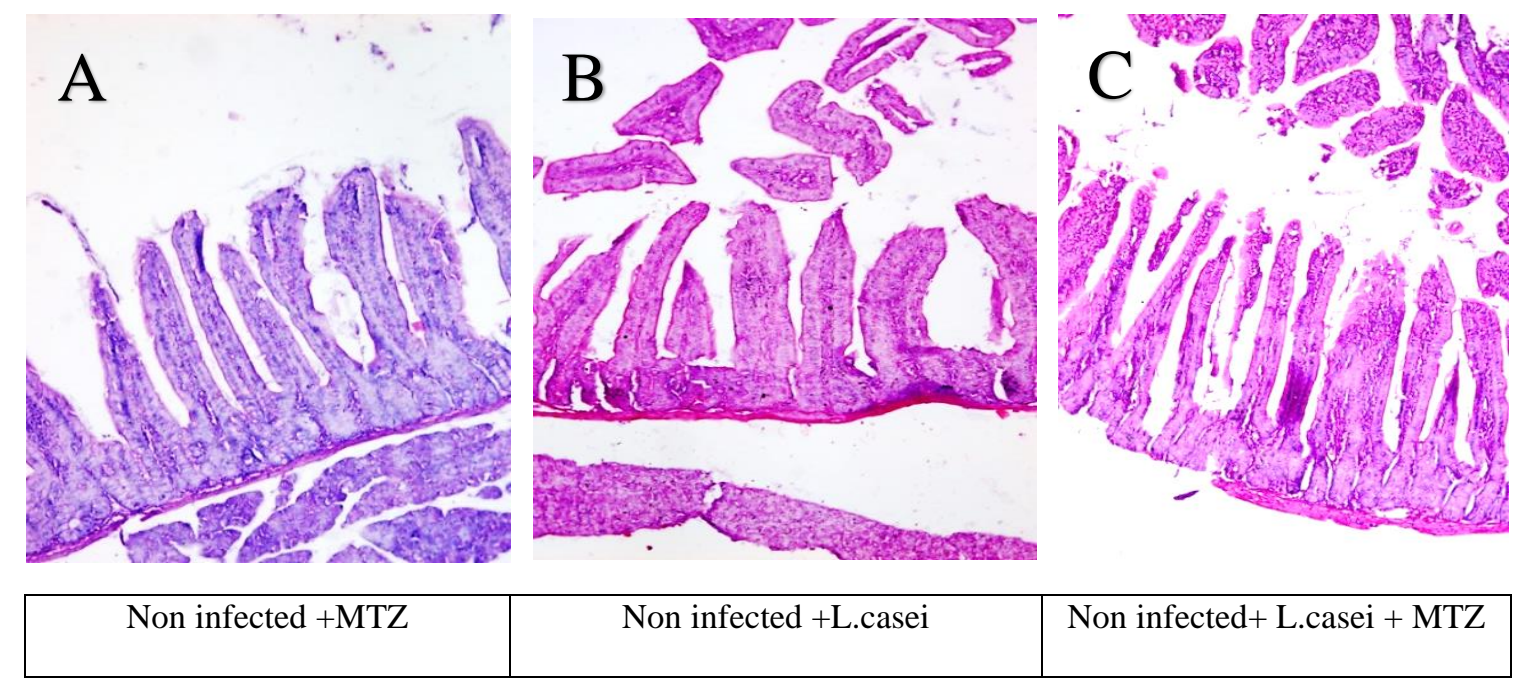

Figure 2. (A, B\&C) Non infected subgroups (S.G.2, 3,4A): Sections from the duodenum, showed unremarkable changes of the villous pattern (H\&E stain X100).

\subsubsection{Infected group:}

1-Infected control subgroup (S.G.1B):

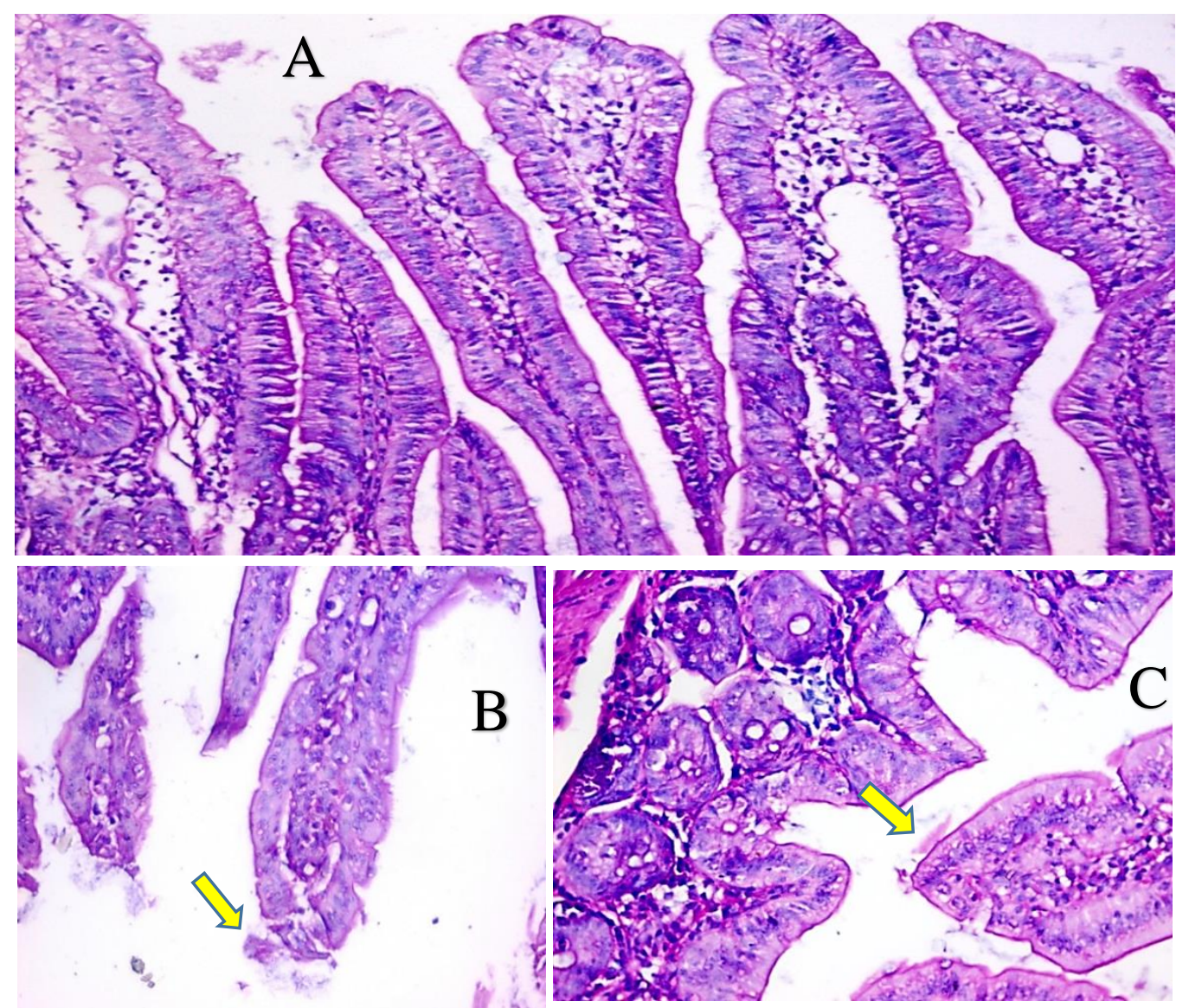

Figure 3. (A, B\&C) Infected control subgroup (S.G.1B): Sections from the duodenum showed shortening and broadening of villi with expansion of the villous core by mononuclear inflammatory cells (red arrows). Some Giardia trophozoites were detected in relation to the surface epithelium (yellow arrows). (A) H\&E stain X200 \& (B, C) X400). 
2- Infected treated MTZ (S.G.2B) subgroup:
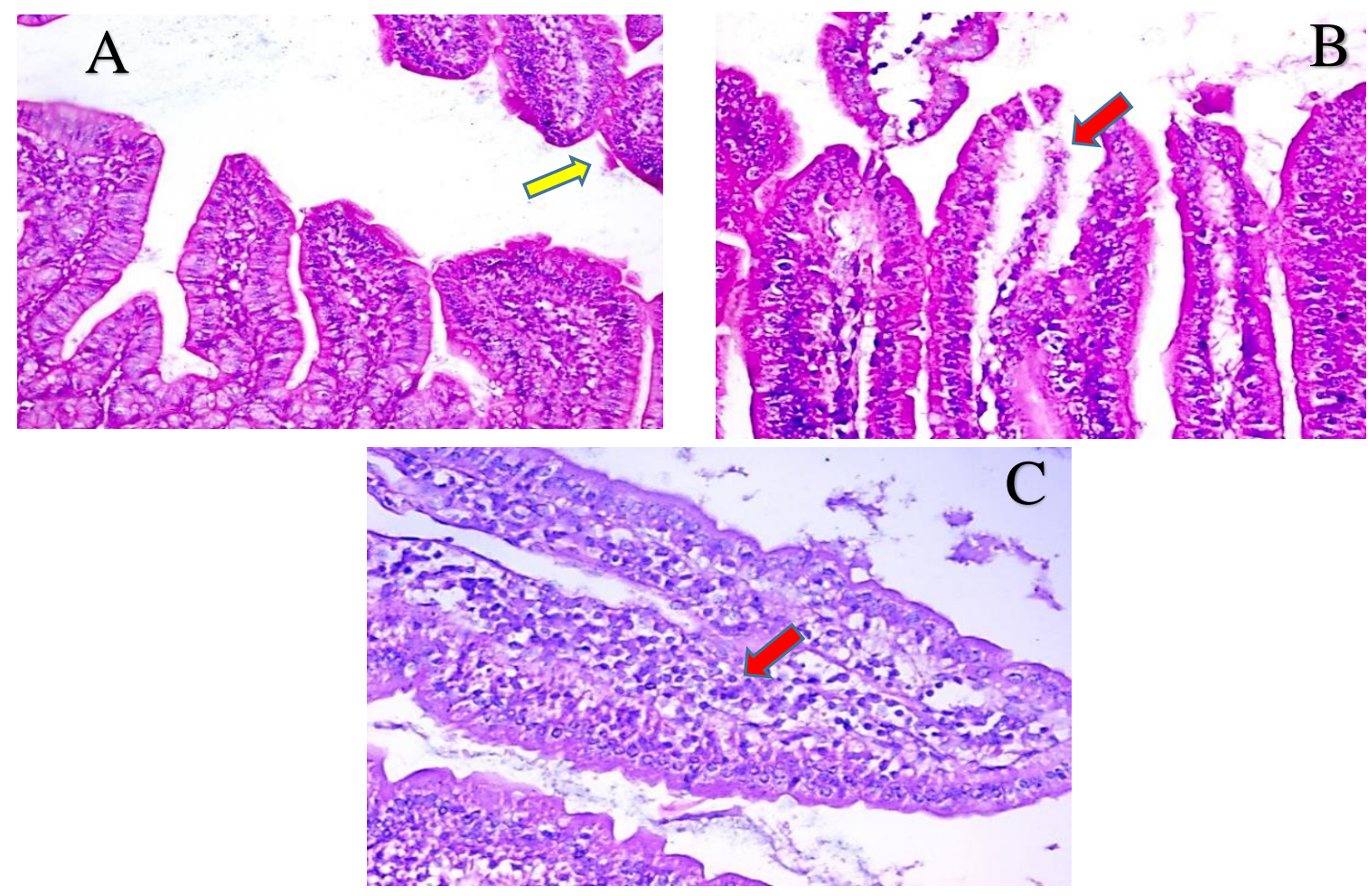

Figure 4. (A, B\&C) Infected treated with MTZ (S.G.2B): Sections from the duodenum showed focal shortening, broadening of villi and moderate mononuclear cellular infiltration (red arrows). Few degenerated Giardia trophozoites could be detected (yellow arrows). (A, B) H\&E stain X100 \& (C) X400.

3- Prophylactic (S.G.3B) subgroup:
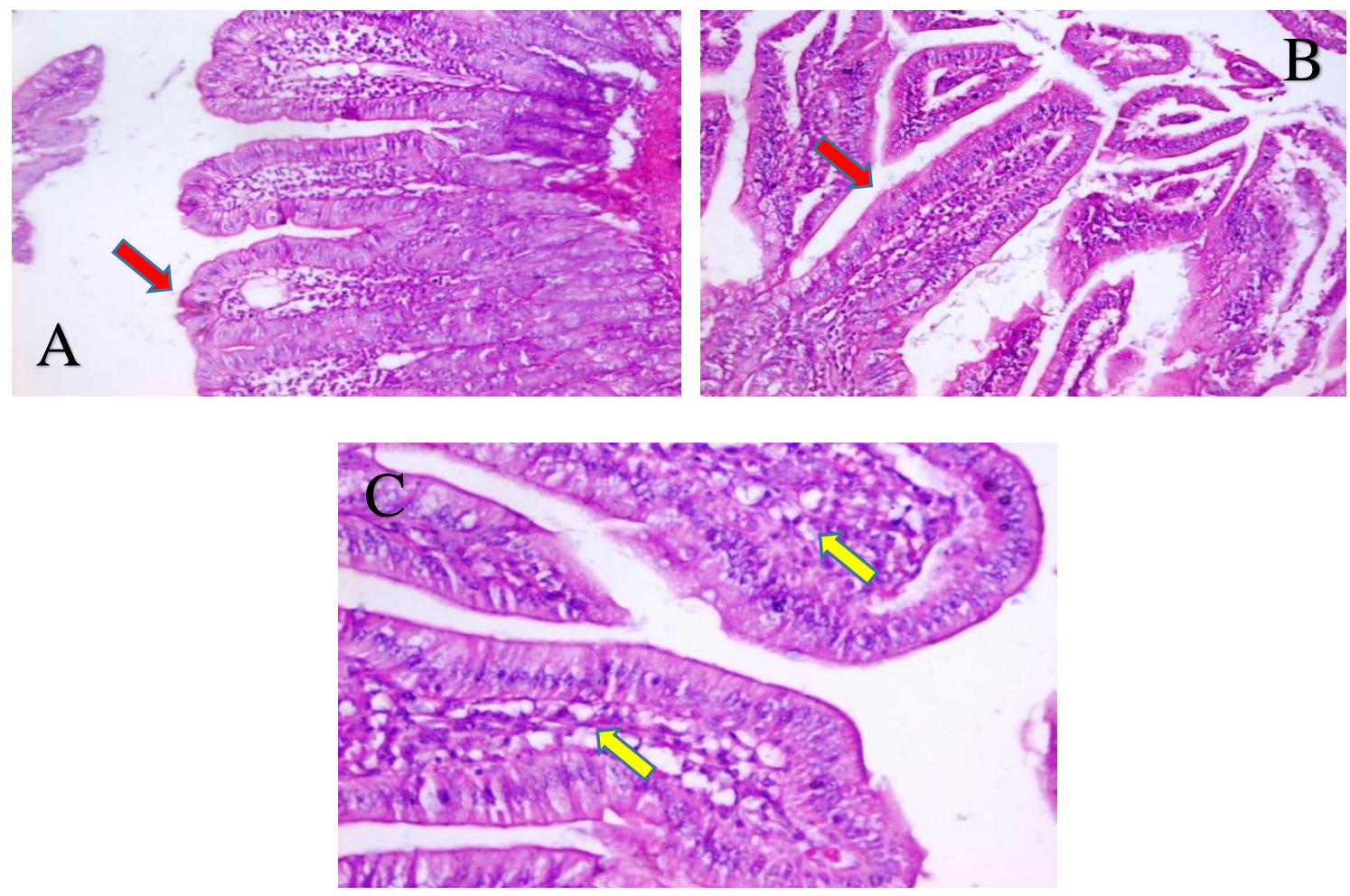

Figure 5. (A, B \&C) Prophylactic (S.G.3B) subgroup: Sections from the duodenum revealed mild broadening and shortening of villi (red arrows) and mild infiltration by mononuclear inflammatory cells (yellow arrows). (A, B) H\&E stain X100 \& (C) X 400 
4- Infected treated L.casei (S.G.4B) subgroup:
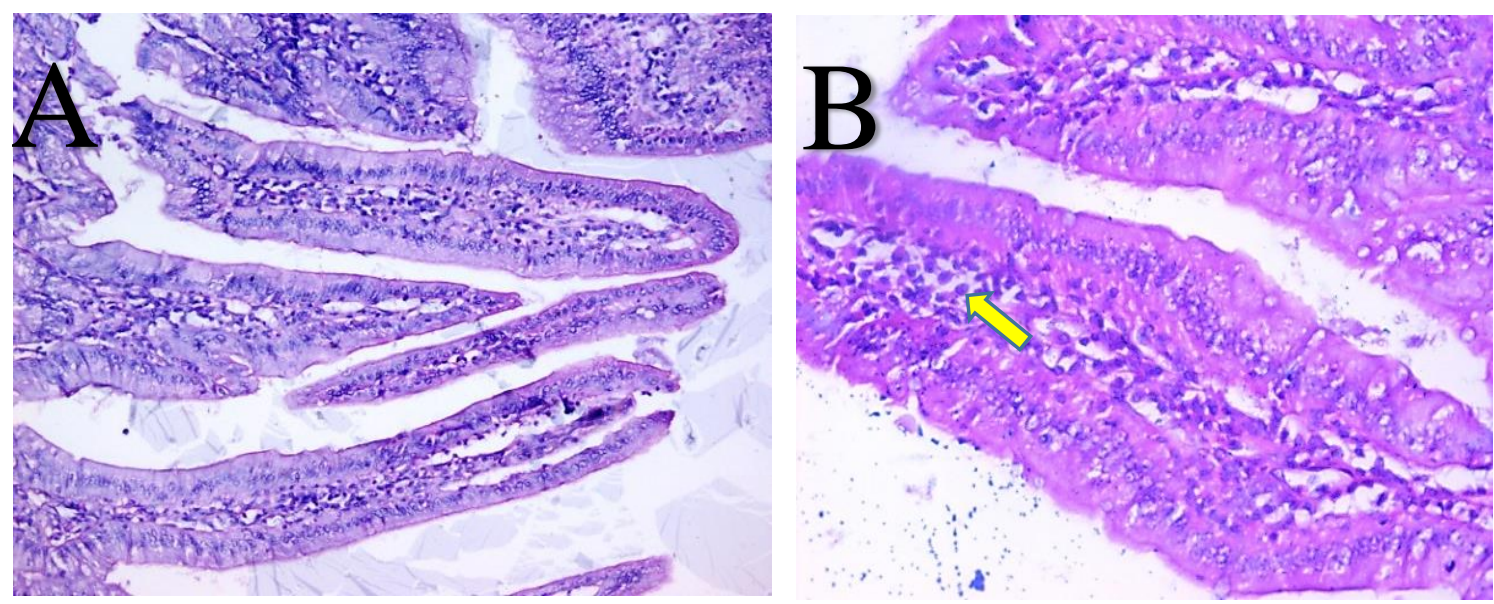

Figure 6. (A\&B) Infected treated L.casei (S.G.4B) subgroup: Sections from the duodenum revealed moderate infiltration by mononuclear inflammatory cells (yellow arrow). (A)H\&E stain X100and (B) X400.

5- Infected treated L.casei \&MTZ (S.G.5B) subgroup:
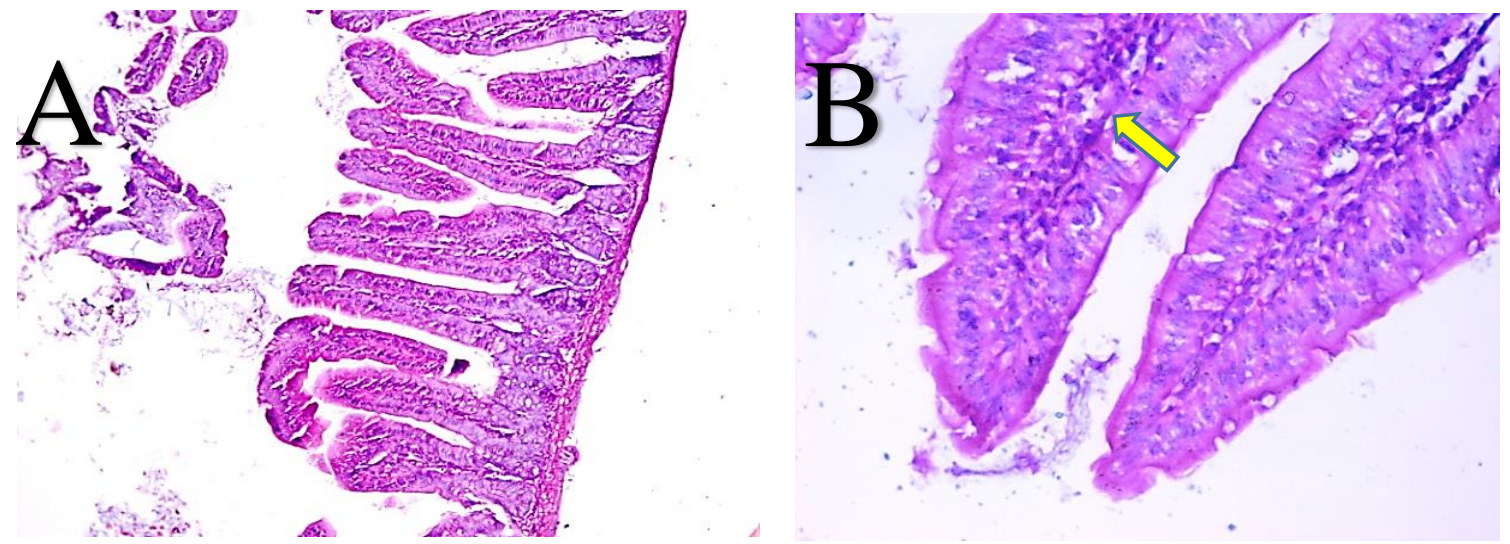

Figure 7. (A\&B) Infected treated L.casei \& MTZ (S.G.5B) subgroup: Sections from the duodenum showed mild infiltration by mononuclear inflammatory cells (yellow arrow).(A)H\&E stainX100\&(B)X400.

\subsection{Immunohistochemical results:}

\subsubsection{Non infected group:}

1- Healthy control subgroup (S.G.1A):
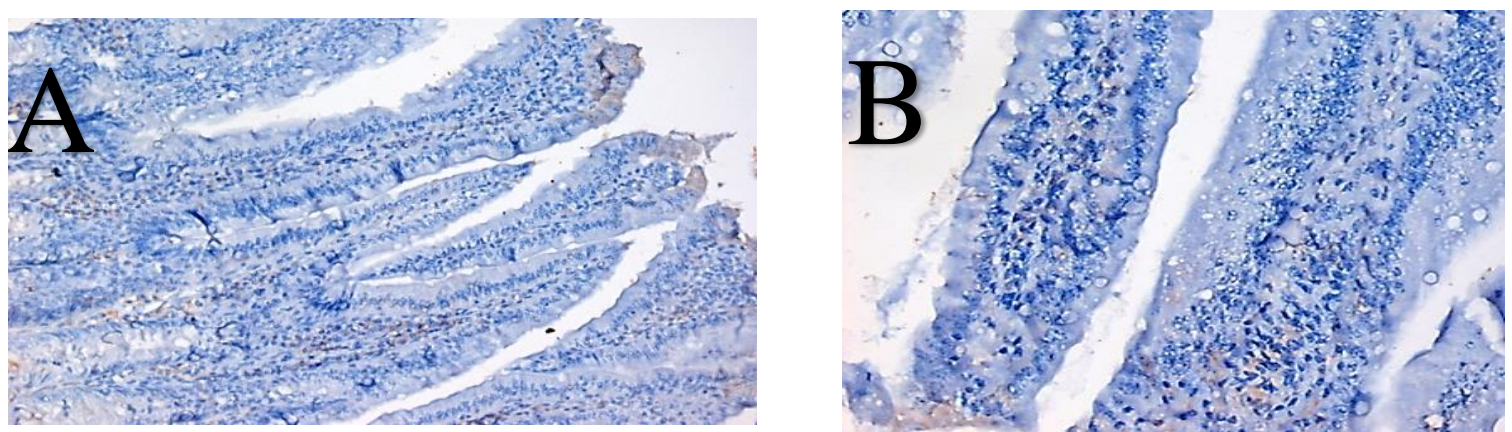

Figure 8. (A\&B) Healthy control subgroup (S.G.1A): sections from the duodenum showed that there were no IgA secretory plasma cells in the lamina propria. Immunohistochemistry stain (A) 200X \& (B)400X. 
2- Non infected received MTZ (S.G.2A) subgroup:
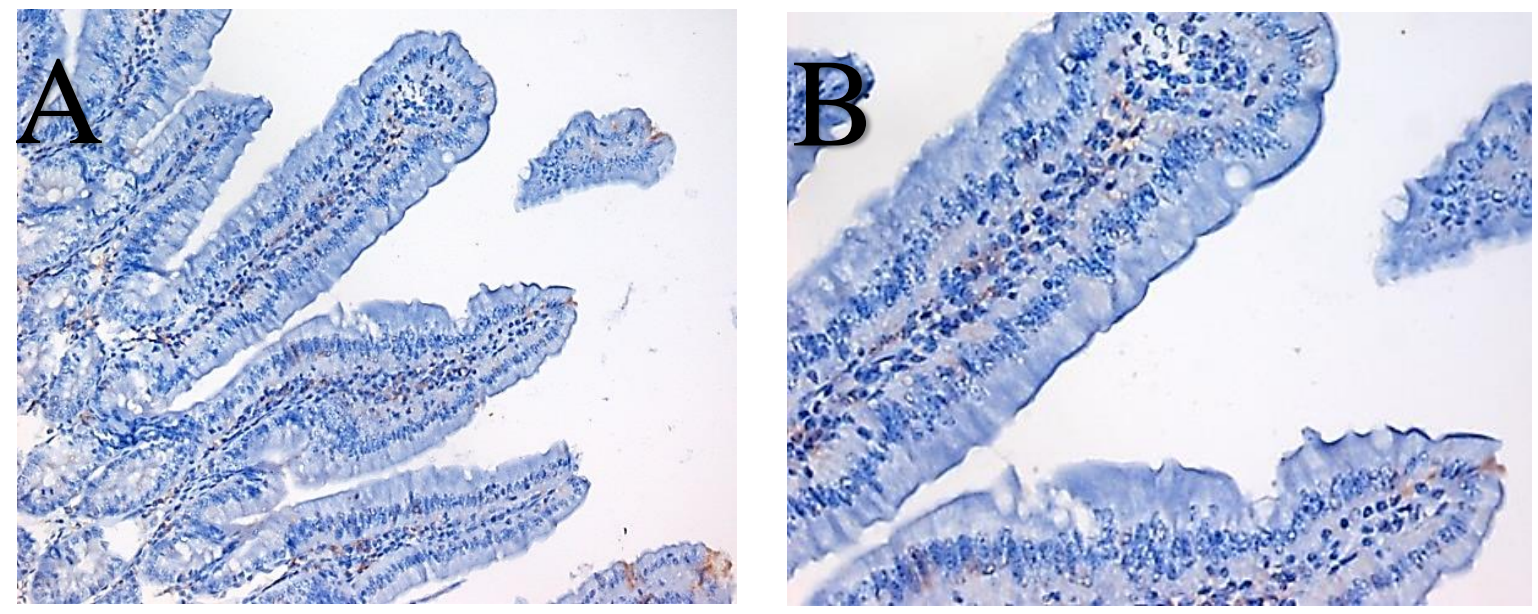

Figure 9. (A\&B) Non infected received MTZ (S.G.2A) subgroup: Sections from the duodenum showed that there were no IgA secretory plasma cells in the lamina propria. Immunohistochemistry stain (A) 200X\& (B) 400X.

3- Non infected received L.casei (S.G.3A) subgroup:
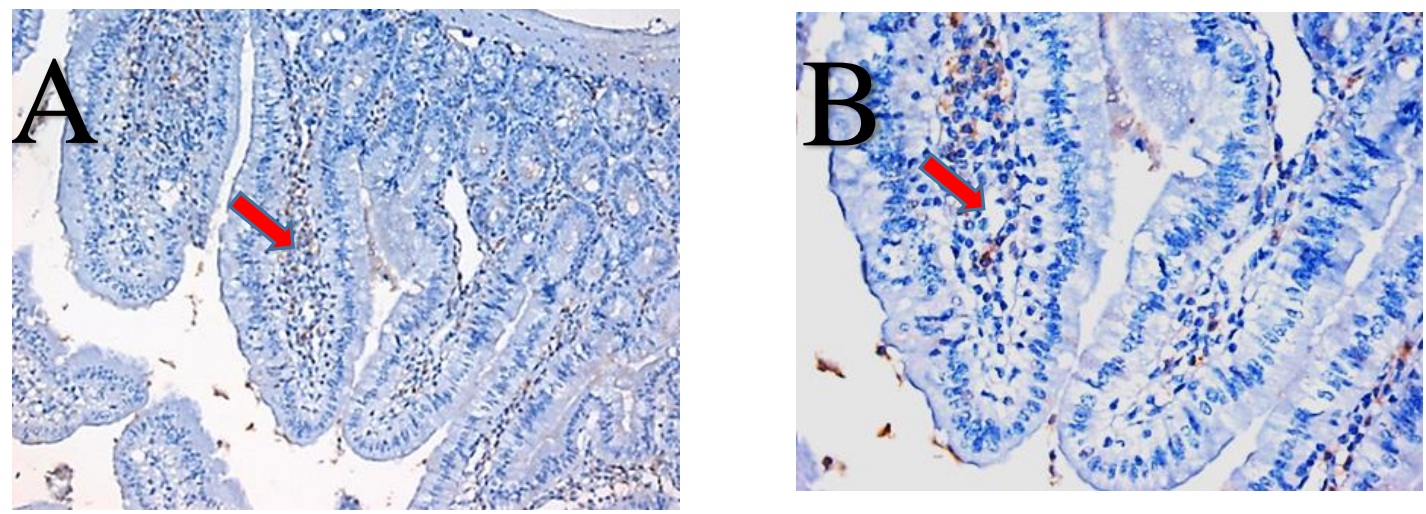

Figure 10. (A\&B) Non infected received L.casei (S.G.3A) subgroup: Sections from the duodenum showed scanty IgA secretory plasma cells in the lamina propria (red arrows). Immunohistochemistry stain (A) 200X \& (B) 400X.

4- Non infected received L.casei \&MTZ (S.G.4A) subgroup:
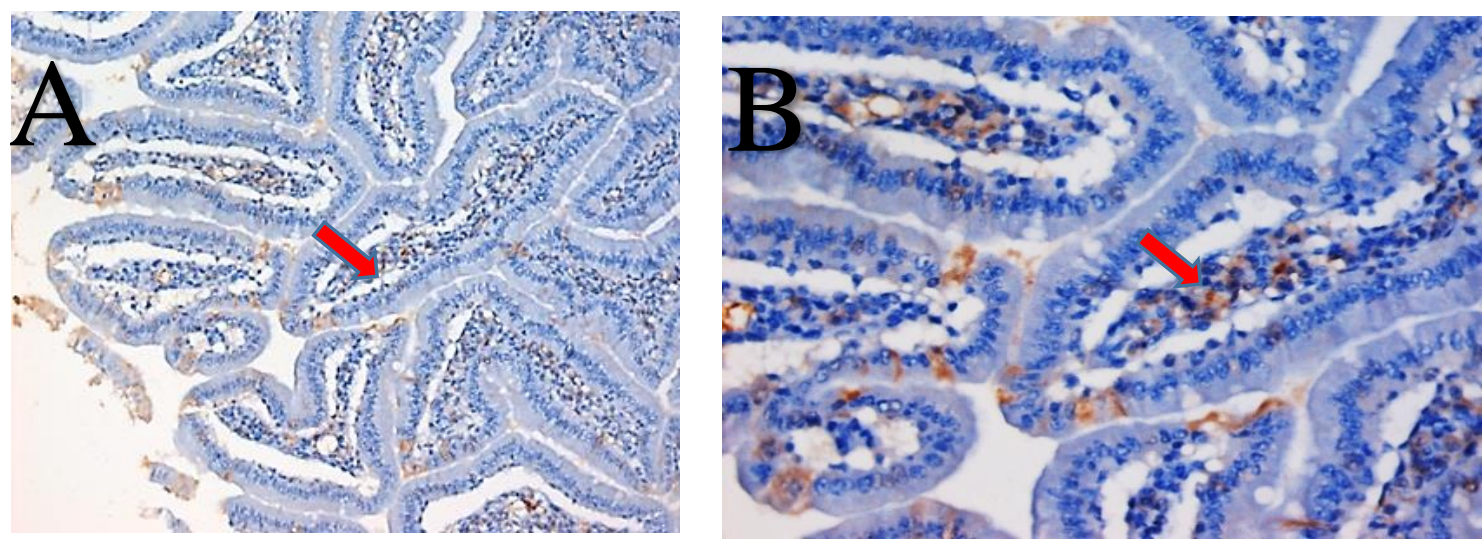

Figure 11. (A\&B) Non infected received L.casei \&MTZ (S.G.4A) subgroup: Sections from the duodenum showed scanty IgA secretory plasma cells in the lamina propria(red arrows). Immunohistochemistry stain (A) 200X \& (B) 400X. 


\subsubsection{Infected group:}

1- Infected control subgroup (S.G.1B):
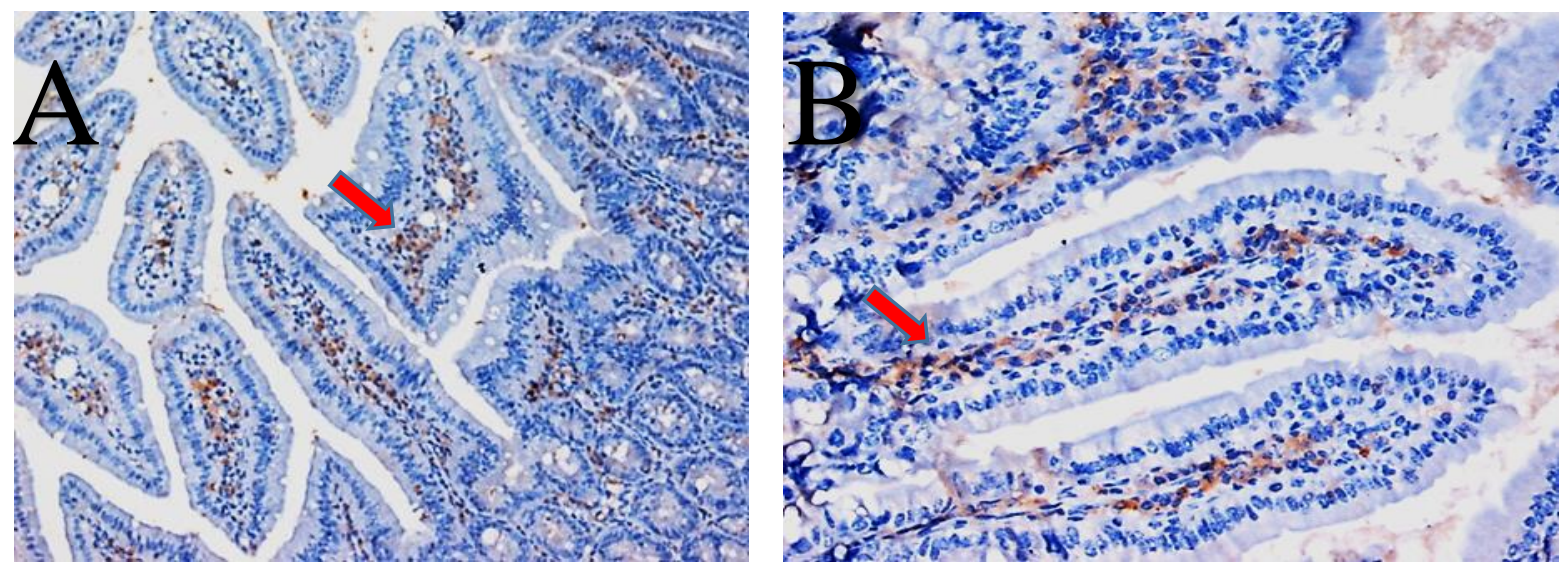

Figure 12. (A\&B) Non infected received L.casei \&MTZ (S.G.4A) subgroup: Sections from the duodenum showed scanty IgA secretory plasma cells in the lamina propria(red arrows). Immunohistochemistry stain (A) 200X \& (B) 400X.

2- Infected treated MTZ (S.G.2B) subgroup:
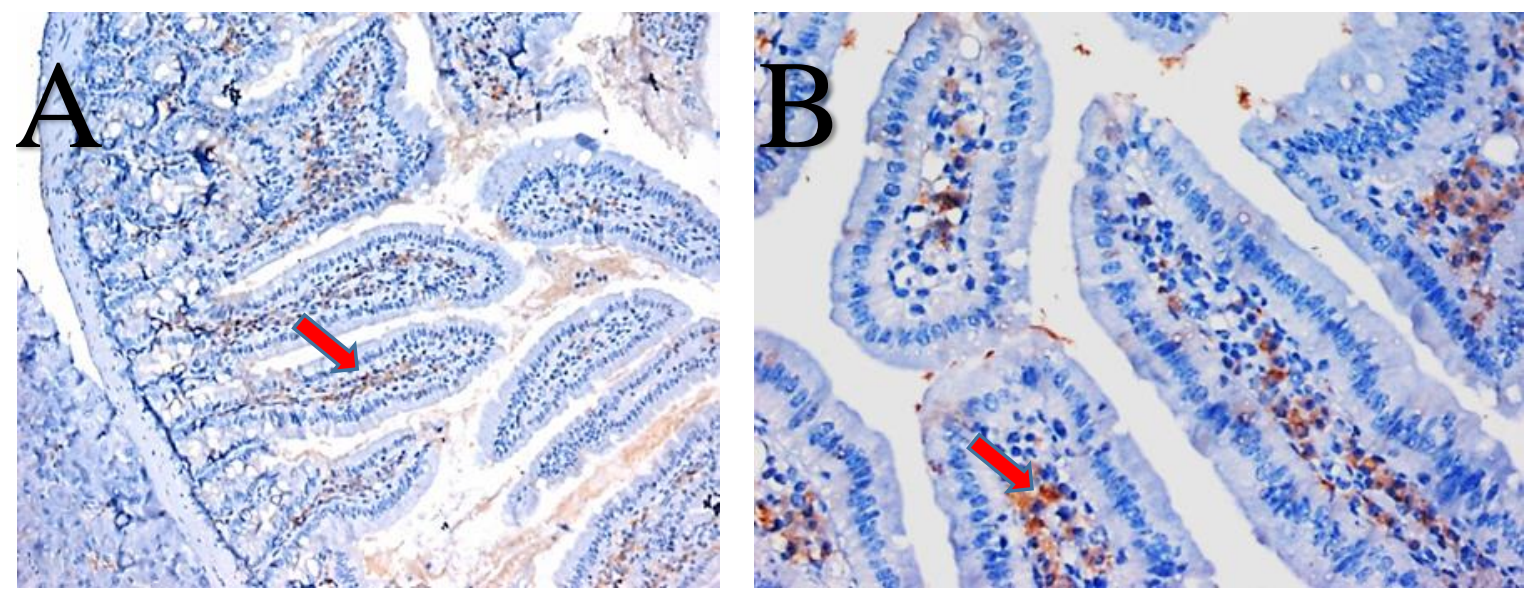

Figure 13. (A\&B) Infected treated MTZ (S.G.2B) subgroup: Sections from the duodenum showed mild increase in IgA secretory plasma cells in the lamina propria (red arrows). Immunohistochemistry stain (A) 200X $\&(\mathrm{~B}) 400 \mathrm{X}$.

3- Prophylactic subgroup (received L.casei before, during and after infection) (S.G.3B):
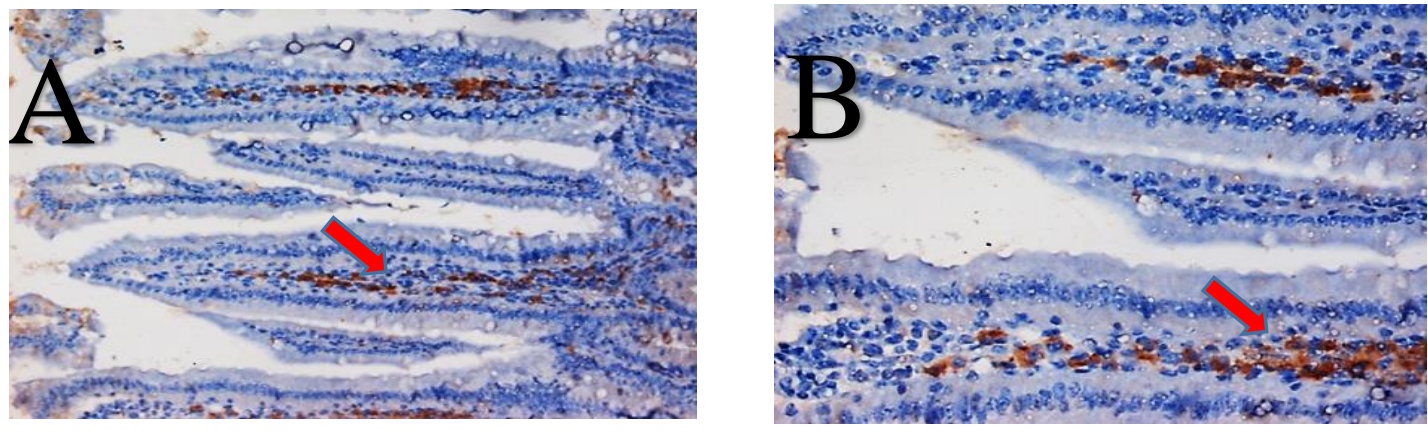

Figure 14. (A\&B) Prophylactic (S.G.3B) subgroup: Sections from the duodenum showed marked increase in IgA secretory plasma cells that appeared as brown color in the lamina propria (red arrows). Immunohistochemistry stain (A) 200X \& (B) 400 X. 
4- Infected treated L.casei (S.G.4B )subgroup:
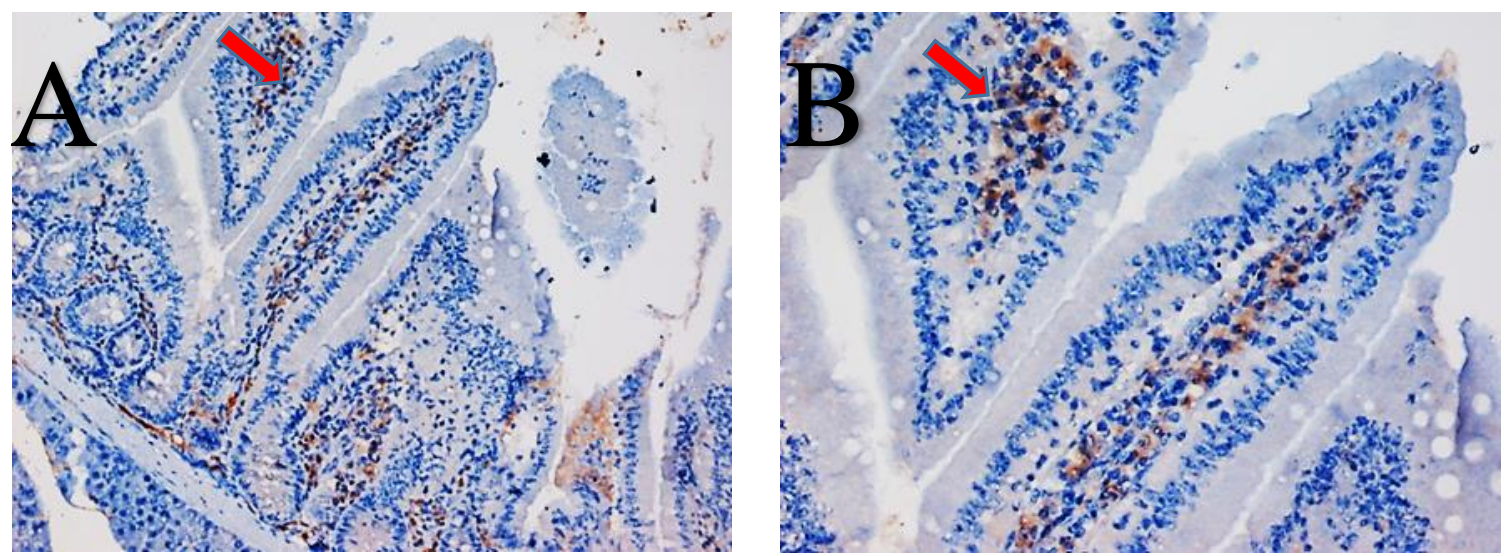

Figure 15. (A\&B) Infected treated L.casei (S.G.4B) subgroup: Sections from the duodenum showed moderate increase in IgA secretory plasma cells in the lamina propria (red arrows). Immunohistochemistry stain (A) $200 \mathrm{X}$ \& (B) 400X.

5- Infected treated L.casei \&MTZ (S.G.5B) subgroup:
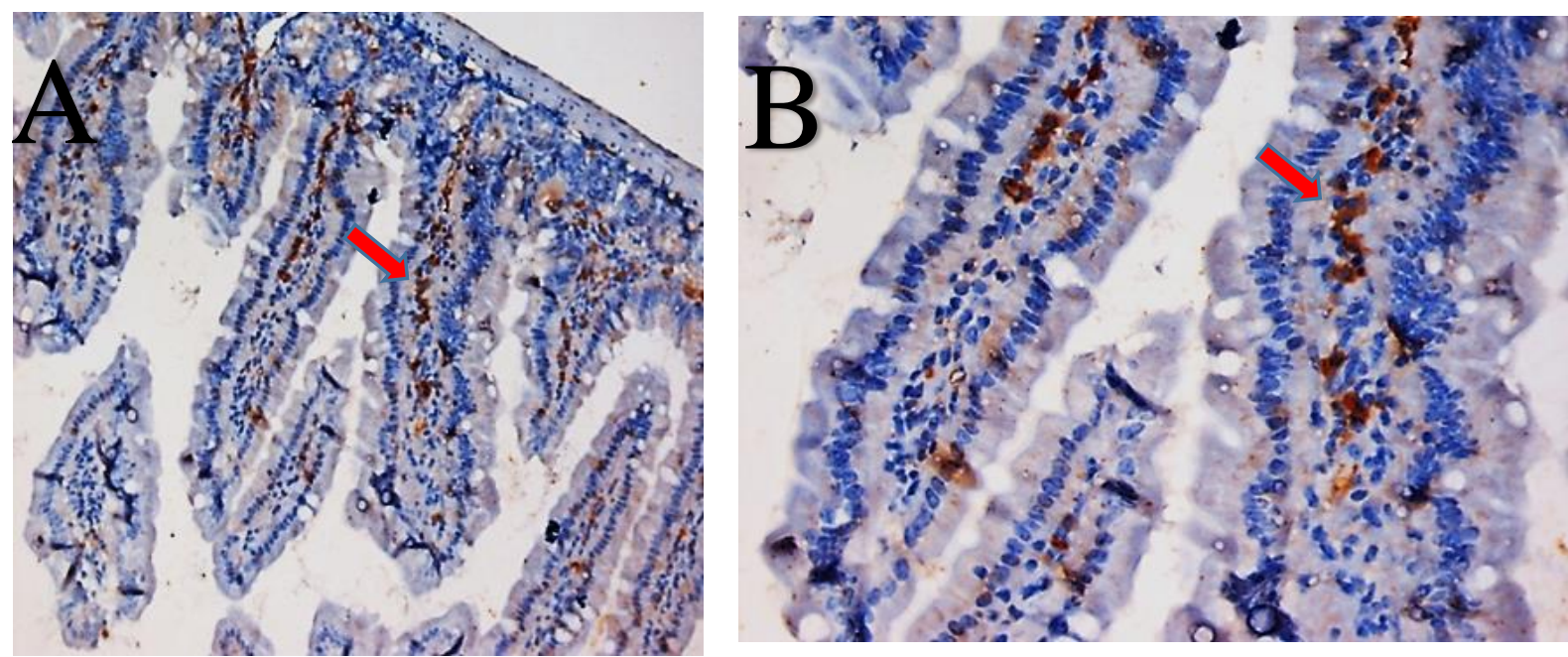

Figure 16. (A\&B) Infected treated L.casei \&MTZ (S.G.5B) subgroup: Sections from the duodenum showed marked increase $\operatorname{IgA}$ secretory plasma cells that appeared as brown color in the lamina propria (red arrows).Immunohistochemistry stain (A) 200X\& (B) 400X.

\section{Discussion}

Giardia lamblia is a protozoan of worldwide distribution which flourishes in the human small intestine .Children are more susceptible to active infection because of high risk of exposure .It is well established that dysfunction of intestinal absorption is commonly associated with giardiasis [18]. Current recommended treatment of giardiasis has considerable adverse effects, treatment failure and drug resistance. Therefore, an urgent call for a new antigiardial alternatives is required [19]. There is a need for natural intervention such as probiotics Lactobacillus bacteria which displays antiprotozoal effect [20].

In the present study probiotic L. casei are evaluated for its anti giardial effect alone and in combination with MTZ in murine giardiasis. Assessment of the effectiveness and cure rate of probiotic L. casei was done by different parasitological, 
histopathological

and

immunohistochemical parameters. In the present study, it was noticed that each treatment model has demonstrated significant reduction of varying degree of the number of Giardia cysts in infected treated (S.G. 2,3,4,5B) subgroups when compared to infected control (S.G.1B) after seven and ten days treatment. The least cyst discharge was observed in prophylactic (S.G.3B) followed by MTZ \& L.casei (S.G.5B) subgroups.

A study done by [21] on the effect of L. casei on giardiasis, it was observed that L. casei fed 7 days prior to Giardia infection was more effective and efficient in eliminating the infection from mice. Also, these results are agreed with [22] who found that the daily administration of Lactobacillus jonhsonii to gerbils, before and after their infection with G. intestinalis, reduced the intensity and longevity of Giardia infection. Perez et al. [23] recorded that, probiotics inhibit giardial growth and induce innate immunological antigiardial mechanisms.

The combination therapy of MTZ and L. casei has reduced the cyst count due to better colonization of Lactobacilli that inhibited the multiplication and adherence of intestinal pathogen [24]. Similarly, Shukla et al. [25] recorded that the combination therapy between L. casei and albendazole had a better effect than using probiotic alone in murine giardiasis. Kelesidis and Pothoulakis, [26] confirmed that Saccharomyces boulardii in combination with metronidazole clears all the symptoms related to giardiasis. Shukla et al. [27] observed the synergistic effect of coadminstration of probiotic and albendazole in Giardia infected mice, resulted in reduction in both of the excretion of Giardia cysts in feces and trophozoite counts in the intestinal fluid. Hawrelak [28] reported that the most beneficial way to treat giardiasis might be through a combination approach utilizing nutritional interventions and therapeutic agents.
Regarding histopathological examination of sections of the duodenum in noninfected mice (G.A), it showed normal villous pattern and the villi with average length and width. Most of the epithelial cells lining are with well-defined brush border and goblet cells are moderate in number.

Histopathological examination of duodenum of infected control subgroup (S.G.1B) in this study revealed profound effect on the structure of the intestinal mucosa in comparison to healthy control (S.G.1A). This effect was in the form of severe villous atrophy, decrease in the ratio of villous height to crypt length and infiltration of lamina propria with inflammatory cells mainly lymphocytes and eosinophils with diffuse loss of brush border of intestinal villi. Additionally, G. lamblia trophozoites were detected in the intestinal lumen and in between the villi. These results are in agreement with many authors [29], [30], and [11].

These findings may be attributed to the fact that, the pathophysiology of acute diarrhea in giardiasis implicates increased rates of enterocytes apoptosis and disruption of the intestinal barrier function. Activation of host lymphocytes (CD8 lymphocyte) mediated shortening of brush border microvilli with or without coinciding villous atrophy and crypt hyperplasia [31]. Histopathological examination of the infected treated MTZ (S.G.2B) subgroup, showed partial improvement in the histopathological changes following Giardia infection. Improvement and healing were detected by persistence of focal broad villi with moderate cellular infiltration and decreased edema in submucosa and muscularis mucosa. These results are in agreement with Ali et al. [32] and Fahmy et al. [33] who reported that there was partial healing of intestinal villi after metronidazole treatment on experimental G. intestinalis infection in vivo study.

Similarly, histopathological findings that were reported by Harba et al. [34] who 
studied the anti-giardial activity of metronidazole in vitro and in vivo. They noticed that MTZ treatment caused some improvement of the intestinal mucosa with restoration of the brush border regularity and decrease in the cellular infiltration of the lamina propria. Also, few villi showed sloughed apical surfaces.

While histopathological examination of prophylactic (S.G.3B) subgroup which were received L. casei before, during and after infection showed remarkable improvement in the form of mild cellular injury with preservation of villus configuration. These results are in agreement with Shukla et al. [21] who reported that probiotic administration protected against parasitic-induced mucosal damage as is evident from the lower cellular injury as compared to the significant damage and increased inflammation in Giardia-infected mice.

Also, Goyal et al. [35] detected in their experimental study that mice fed with probiotic, either prior or simultaneously with Giardia infection had almost normal morphology of jejunal villous enterocytes. Histopathological examination of the infected treated L. casei (S.G.4B) subgroup showed moderate infiltration by mononuclear inflammatory cells. However, damage in small intestine of mice was less compared to infected control (S.G.1B) and MTZ (S.G.2B) treated mice, but also more than prophylactic (S.G.3B) subgroup. Also, histopathological examination of infected treated MTZ \& L. casei (S.G.5B) subgroup showed mild infiltration by mononuclear inflammatory cells and mild shortening of villi without complete restoring of villi and crypts. These results are in agreement with Shukla et al. [21] who demonstrated similar effect of L. casei on giardiasis.

Concerning the immunehistochemical results of duodenal sections from noninfected mice (G.A) in the present study, it showed that there was no $\operatorname{Ig} \mathrm{A}$ secretory plasma cells in lamina propria in both healthy control (S.G.1A) and MTZ (S.G.2A) subgroups while, there was scanty IgA secretory plasma cells in both L. casei (S.G.3A) and in MTZ \& L. casei (S.G.4A) subgroups.

Borjas et al. [36] reported that secretory $\operatorname{Ig} \mathrm{A}(\mathrm{s} \operatorname{Ig} \mathrm{A})$ is the predominant antibody in the intestinal lumen and probably the most important defense mechanism involved against parasite infection. Rodríguez et al. [37] recorded that the production of $\operatorname{sIgA}$ antibody occurs during active Giardia infection; therefore, the determination of sIgA may be an important tool for monitoring the course of Giardia infection. These results are in agreement with Fernández et al. [38] who demonstrated that oral administration of probiotics increased the number of $\operatorname{IgA}$ cells in the lamina propria of the intestine and also in bronchus and mammary glands. De Moreno et al. [39] reported that probiotics induce the $\operatorname{IgA}$ cycle, reinforce and maintain the immune surveillance in mucosal sites distant from the gut mucosa. Also, the results in non-infected MTZ (S.G.2A) subgroup are in agreement with Zhang et al. [40] who evaluated the effect of infusion of antibiotics on pigs; $10 \mathrm{~mL}$ saline solution with antibiotic ampicillin, gentamicin and metronidazole via $\mathrm{T}$ cannula leaded to decrease systemic and intestinal immunoglobulins concentrations. In their study there were a decrease in the concentrations of $\operatorname{sIgA}$ and $\operatorname{IgG}$ in the jejunal mucosa and $\operatorname{sig} \mathrm{A}$ in the colonic mucosa. The low concentrations of intestinal $\operatorname{IgA}$ in the pigs administrated with antibiotic may indicate a decrease in defensive capacity of the mucosal immune system.

The immunohistochemical result of duodenal sections from infected mice (G.B) in the current study, showed that there were mild $\operatorname{Ig}$ A secretory plasma cells in infected control (S.G.1B) and MTZ (S.G.2B) subgroups, moderate cells in L.casei (S.G.4B) subgroup, while there were marked increase of IgA secretory plasma cells in prophylactic (S.G.3B) and MTZ \& L. casei (S.G.5B) subgroups. These results are in agreement with Toma \& Al- 
Hadraawy [41] who showed increase in anti-Giardia intestinal fluid IgA antibodies in infected humans. It has also been reported that people with SIgA deficiencies are more susceptible to infection by $\mathrm{G}$. intestinalis.

Our results are in agreement with Shukla et al. [25] who reported that oral administration of the probiotic Lactobacilli to Giardia-infected mice 7 days prior to or simultaneously with the challenge dose of Giardia trophozoites, restores the normal gut microbiota and modulates the mucosal immune response, since a significant increase in the levels of specific secretory $\operatorname{IgA}$ antibody and $\operatorname{IgA}+$ cells were observed.

The current study is in agreement with Galdeano and Perdigon, [42] who studied the effect of probiotic bacterium L. casei on activation of the gut mucosal immune system through innate immunity. The bacterium was orally administered to $\mathrm{BALB} / \mathrm{c}$ mice. After, they were sacrificed; the small intestine and intestinal fluids were collected to measure sIgA specific for L. casei. They noticed that IgA cells and IL-6producing cells increased after 7 days of $\mathrm{L}$. casei administration.

Similarly, Benyacoub et al. [43] demonstrated the ability of probiotic Enterococcus faecium SF68 in the improvement of specific anti-Giardia immune response in mice. Oral feeding of E. faecium strain SF68 starting 7 days before inoculation with Giardia trophozoites significantly increased the production of specific anti-Giardia intestinal $\operatorname{IgA}$ and blood IgG. This improvement also was characterized by consequent decline of the enteric parasitic and antigenic overload. In addition, a higher proportion of CD4+ $\mathrm{T}$ cells in Payer's patches and spleen could be observed, suggesting that this probiotic might be useful in the treatment of Giardia infection.
In addition to competitive inhibition, the attachment of probiotics to enterocytes may have increased the synthesis of nitric oxide, enhanced mucosal immunity in terms of increased production of secretary $\operatorname{IgA}$, systemic IgG and cytokines that may have inhibited the growth and replication of Giardia trophozoites leading to reduced gut inflammation [44].

In conclusion probiotics have demonstrated a significant potential as therapeutic options for giardiasis. They have immunomodulating properties, regulate inflammation in a number of ways and enhance the epithelial barrier function to prevent chronic inflammation in the gut. The oral administration of probiotics is thought to reinforce the physiological functions of gut microbiota at the intestinal level and is able to fight against pathogens. Probiotics, mainly strains of Lactobacillus species, come from dairy products must be used in dietary supplements, food, infant formulations and medical devices or even as a daily routine diet. 


\section{References}

1. Beyhan, Y.E. \& Cengiz, Z.T. (2017): Comparison of microscopy, ELISA and real-time PCR for detection of Giardia intestinalis in human stool specimens. Turk. J. Med. Sci.; 47: 1295-1299.

2. Eckmann, L. \& Gillin, F. D. (2001): Microbes and microbial toxins: paradigms for microbial-mucosal interactions. Pathophysiological aspects of enteric infections with the lumen-dwelling protozoan pathogen Giardia lamblia. American Journal of Physiology-Gastrointestinal and Liver Physiology; 280 (1): 1-6.

3. Goyal, N.; Tiwari, R. P. \& Shukla, G. (2011): Lactobacillus rhamnosus GG as an effective probiotic for murine giardiasis. Interdisciplinary Perspectives on Infectious Diseases.

4. Abdel-Moein, K. A. \& Saeed, H. (2017): The zoonotic potential of Giardia intestinalis assemblage $\mathrm{E}$ in rural settings. Parasitology Research; 115(8): 3197-3202.

5. Goyal, N.; Rishi, P. \& Shukla, G. (2013): Lactobacillus rhamnosus GG antagonizes Giardia intestinalis induced oxidative stress and intestinal disaccharidases: an experimental study. World Journal of Microbiology and Biotechnology; 29(6): 1049-1057.

6. Despommier, D. D.; Griffin, D.O.; Gwadz, R.W.; et al. (2018): "III. Eukaryotic Parasites". Parasitic Diseases (6ed.). Parasites Without Borders; pp 11-17.

7. Gardner, T. B. \& Hill, D. R. (2001): Treatment of giardiasis. Clinical
Microbiology Reviews; 14(1): 114128.

8. Lemee, V.; Zaharia, I.; Nevez, G.; et al. (2000): Metronidazole and albendazole susceptibility of 11 clinical isolates of Giardia duodenalis from France. Journal of Antimicrobial Chemotherapy; 46(5): 819-821.

9. Obendorf, J.; Viveros, P. R.; Fehlings, M.; et al.(2013): Increased expression of $\mathrm{CD} 25, \mathrm{CD} 83$, and $\mathrm{CD} 86$ and secretion of IL-12, IL-23 and IL-10 by human dendritic cells incubated in the presence of Toll-like receptor 2 ligands and Giardia duodenalis. Parasites \& Vectors; 6(1): 317.

10. Garcia, L.S. (2007): Intestinal Protozoa: Flagellates and Ciliates. Diagnostic Medical Parasitology. ASM press, Washington D.C.; Part II: 771812.

11. Dyab, A. K.; Yones, D. A.; Ibraheim, Z. Z.; et al. (2016): Anti-giardial therapeutic potential of dichloromethane extracts of zingiber officinale and curcuma longa in vitro and in vivo. Parasitology Research; 115 (7): 2637-2645.

12. Esboei, R. B.; Ebrahimzadeh, M. A.; Gholami, S. H.; et al. (2013): Antigiardial activity of Sambucus ebulus. Eur.Rev. Med. Pharmacol .Sci.; 17(15): 2047-2050.

13. De Man, J. C.; Rogosa, D. M. \& Sharpe, M. E. (1960): A medium for the cultivation of lactobacilli. Journal of Applied Bacteriology; 23(1): 130135.

14. Brandelli, C.L.; Giordani, R.B.; De Carli, G.A.; et al. (2009): Indigenous traditional medicine: in vitro anti- 
giardial activity of plants used in the treatment of diarrhea. Parasitol. Res.; 104:1345-1349.

15. Fonseca, J. F.; Alvim, L. B.; Nunes, A.C.; et al. (2019): Probiotic effect of Bifidobacterium longum 51A and Weissella paramesenteroides $\mathrm{WpK} 4$ on gerbils infected with Giardia lamblia. Journal of Applied Microbiology ISSN; 1364-5072

16. Ross, M.; Michael, H.; Pawlina.; et al. (2016): Histology: a text and atlas: with correlated cell and molecular biology (7th ed.). Wolters Kluwer; pp. 984 p.

17. Huiyan, M.; Yani, L.u.; Marchbanks, P.A; et al. (2013): Quantitative measures of estrogen receptor expression in relation to breast cancerspecific mortality risk among white women and black women. J.Breast. Cancer. Res.; 15(5): 90-99.

18. Wielinga, C.; Thompson, R. A.; Monis, P.; et al. (2015): Identification of polymorphic genes for use in assemblage $\mathrm{B}$ genotyping assays through comparative genomics of multiple assemblage B Giardia duodenalis isolates. Molecular and Biochemical parasitology; 201(1): 1-4.

19. Long, K. Z.; Rosado, J. L.; Montoya, Y.; et al. (2007): Effect of vitamin A and zinc supplementation on gastrointestinal parasitic infections among Mexican children. Pediatrics; 120(4): e846-e855.

20. Hart, C. J.; Munro, T.; Andrews, K. T.; et al. (2017): A novel in vitro imagebased assay identifies new drug leads for giardiasis. International Journal for Parasitology: Drugs and Drug Resistance; 7(1): 83-89.
21. Shukla, G., Devi, P. \& Sehgal, R. (2008). Effect of Lactobacillus casei as a probiotic on modulation of giardiasis. Digestive Diseases and Sciences; 53(10): 2671-2679.

22. Humen, M.A.; De Antoni, G.L; Benyacoub, J.; et al. (2005): Lactobacillus johnsonii La1 antagonizes Giardia intestinalis in vivo. Infect. Immun.; 73(2):1265-1269.

23. Benyacoub, J.; Perez, P. F.; Rochat, F.; et al. (2005): Enterococcus faecium SF68 enhances the immune response to Giardia intestinalis in mice. The Journal of Nutrition; 135(5): 11711176 .

24. Ghanaei, M. F.; Dehbashi, N.; Yazdanparast, K.; et al. (2003): Efficacy of Saccharomyces boulardii with antibiotics in acute amoebiasis. World Journal of Gastroenterology: W.J.G.; 9(8): 1832.

25. Shukla, G.; Kaur, H. \& Sharma, L. (2013): Comparative therapeutic effect of probiotic Lactobacillus casei alone and in conjunction with antiprotozoal drugs in murine giardiasis. Parasitology Research; 112(6): 21432149.

26. Kelesidis, T. \& Pothoulakis, C. (2012): Efficacy and safety of the probiotic Saccharomyces boulardii for the prevention and therapy of gastrointestinal disorders. Therapeutic Advances in Gastroenterology; 5(2): 111-125.

27. Shukla, G.; Sharma, G. \& Goyal, N. (2010): Probiotic characterization of lactobacilli and yeast strains isolated from whey beverage and therapeutic potential of Lactobacillus yoghurt in 
murine giardiasis. Am. J. Biomed. Sci.; 2: $248-261$.

28. Hawrelak, J. (2003): Giardiasis: pathophysiology and management. Alternative Medicine Review; 8:129142.

29. Chin, A. C.; Teoh, D. A.; Scott, K. G. E.; et al. (2002): Strain-dependent induction of enterocyte apoptosis by Giardia lamblia disrupts epithelial barrier function in a caspase-3dependent manner. Infection and Immunity; 70(7): 3673-3680.

30. Mahmoud, A.; Attia, R.; Safaa, S. A. I. D.; et al. (2014): Ginger and cinnamon: can this household remedy treat giardiasis? Parasitological and histopathological studies. Iranian Journal of Parasitology; 9(4): 530.

31. Ventura, L. L. A.; Oliveira, D. R. D.; Gomes, M. A.; et al. (2018): Effect of probiotics on giardiasis. Where are we? Brazilian Journal of Pharmaceutical Sciences; 54(2).

32. Ali, A. A.; Abdelrahim, M. E.; Elmoslamy, N. A.; et al. (2014): Comparison between nitazoxanide and metronidazole in the treatment of protozoal diarrhea in children. Medicine Science; 3(2): 1162-73.

33. Fahmy, Z.H.; Aly, E.; shalsh, I.; et al. (2014): The effect of medium chain saturated fatty acid (monolaurin) on levels of the cytokines on experimental animal in Entamoeba histolytica and Giardia lamblia infection. J.A.P.P.; 8(4):106-114.

34. Harba, N.M.; Khair, N.S. \& Azzaz, M.F. (2019): Anti-giardial activity of the aqueous extracts of cymbopogon citratus leaves (Lemongrass) and pulicaria undulata herb in comparison with metronidazole, in vitro and in vivo. Egyptian Journal of Medical Microbiology Volume; 28 / No.3.

35. Goyal, N.; Tiwari, R. P. \& Shukla, G. (2011): Lactobacillus rhamnosus GG as an effective probiotic for murine giardiasis. Interdisciplinary Perspectives on Infectious Diseases.

36. Borjas, R. D. M.; Rivadeneyra, D. J.; Leyva, D.A.; et al. (1998): Secretory immune response to membrane antigens during Giardia lamblia infection in humans. Infection and Immunity; 66(2): 756-759.

37. Rodríguez, O. L.; Hagel, I.; González, Y.; et al. (2004): Secretory $\operatorname{IgA}$ antibody responses in Venezuelan children infected with Giardia duodenalis. Journal of Tropical Pediatrics; 50(2): 68-72.

38. Fernández, M. F.; Boris, S. \& Barbes, C. (2003): Probiotic properties of human lactobacilli strains to be used in the gastrointestinal tract. Journal of Applied Microbiology; 94(3): 449-455.

39. De Moreno, A.; Galdeano, C. M.; Chaves, S.; et al. (2005): Oral administration of $\mathrm{L}$. casei CRL 431 increases immunity in bronchus and mammary glands. European Journal of Inflammation; 3(1): 23-28.

40. Zhang, C.; Peng, Y.; Mu, C.; et al. (2018): Ileum terminal antibiotic infusion affects jejunal and colonic specific microbial population and immune status in growing pigs. Journal of Animal Science and Biotechnology; 9(1): 51.

41. Toma, R. S. \& Al-Hadraawy, S. K. (2018): Trefoil factor3 (TFF3), 
Calprotectin (CALP) and (SIgA) as immunological markers in patients infected with Giardia lamblia Parasite. Journal of Pharmaceutical Sciences and Research; 10(9): 2221-2224.

42. Galdeano, C. M. \& Perdigon, G. (2006): The probiotic bacterium Lactobacillus casei induces activation of the gut mucosal immune system through innate immunity. Clin. Vaccine Immunol.; 13(2): 219-226.

43. Benyacoub, J.; Perez, P. F.; Rochat, F.; et al. (2005): Enterococcus faecium SF68 enhances the immune response to Giardia intestinalis in mice. The Journal of Nutrition; 135(5): 11711176.

44. Shukla, G.; Bhatia, R. \& Sharma, A. (2016): Prebiotic inulin supplementation modulates the immune response and restores gut morphology in Giardia duodenalisinfected malnourished mice. Parasitology Research; 115(11): 41894198. 